\title{
A CONTRIBUIÇÃO DO ESTÁGIO SUPERVISIONADO NO DESEN VOLVIMENTO DE APTIDÕES E FORMAÇÃO DE COMPETÊNCIAS
}

M s. M aria Antonia M. SCH WART Z* M s. N eusa M aria Gomide BAPTISTA*

M s. Vera Lúcia CAST ELEIN S**

\section{Resumo}

0 presente trabalho trata da organização dos estágios curriculares no currículo dos diferentes cursos superiores e está articulado ao Projeto de pesquisa sobre "O rganização e Planejamento de estágios da PU CPR." Refere-se ao desenvolvimento de aptidões e competências previstas nos diferentes programas de aprendizagem do projeto pedagógico dos cursos de graduação e a importância de que se revestem os estágios para a formação profissional adequada do estudante. 0 estágio como experiência pré-profissional volta-separa o desenvolvimento de ações vivenciadas, reflexivas e críticas. É um Programa de aprendizagem com características especiais, como elemento integrador e interdisciplinar oportunizando a inserção de alunos e professores na realidade profissional existente.

Palavras-chave: Estágio, currículo, aptidões e competências, formação profissional, interdisciplinaridade.

\section{Abstract}

This work deals with the organization of curriculum field practice in the curricula of different higher education courses, and is related to the reseach project "O rganization and Planning of Field Practice" . It refers to the development of skills and attitudes as planned for the various undergraduate courses' learning programs and to the importance of the field practices for a professional training meaninful to the student. The field practice as preprofessional experience turns towards the development of lived, reflexive and

- Prof. Adjunto 3 da PUCPR. M estre em Educação

- Prof. Adjunto 3 da PU CPR. M estre em Educação

-.. Prof. Assistentel da PU CPR. M estre em Educação 
critical actions. It is a Leaning Program with special characteristics, being an element for interdisciplinarity, which brings about the opportunity for the integration of both students and teachers in the existing professional context.

Keywords: Field practice, curriculum, attitudes, professional training, interdisciplinarity.

\section{1 - Introdução}

Este trabal ho está articulado à pesquisa realizada em instituição de ensino superior, nos anos de 2000 e 2001 sobre a "O rganização e Planejamento de Estágios."

Estágio Supervisionado éum dos pontos chave de um projeto pedagógico, pois é o espaço onde a identidade profissional do aluno é gerada, por isso mesmo, deve ser de uma ação vivenciada, reflexiva e crítica, constituindo-se num momento especial de articulação dos conhecimentos teóricos e práticos. Assim, urge repensar o Estágio Supervisionado como parte integrante dos Programas de A prendizagem dos cursos da Instituição e o seu papel na descoberta das competências profissionais.

A partir do desenvolvimento da pesquisa sobre "O rganização e Planejamento dos Estágiosna PU CPR" foi possível identificar al gumas questões defundamental importância relacionadas ao papel dos estágios no desenvolvimento de aptidões e formação de competências necessárias para se lidar com as situações que se apresentam no mundo do trabalho os futuros profissionais. $\mathrm{Na}$ PU CPR foram propostos novos projetos pedagógicos cuja suplementação teve início em 2000 etais propostas buscam ultrapassar práticas pedagógicas conservadoras com o intuito de formar o cidadão-trabal hador que possa dar conta das exigências que se colocam para as profissões neste novo milênio.

Ao centrar o foco da atenção na aprendizagem dos alunos propôs uma nova estruturação curricular, deixando de organizar o conhecimento e disciplinas com a proposi ção dos "Programas de aprendizagem" organizados a partir das aptidões/competências/habilidades definidas pelos cursos que, por sua vez, orientam a metodologia e a avaliação da apren dizagem. N esta nova proposta o está gio passa a ter grande relevância, pois ofertado desde o início do curso, poderá contribuir com uma formação de maior qualidade. 


\section{2 - O s estágios como programa de aprendizagem}

O Estágio Supervisionado é um Programa de Aprendizagem com características especiais, apresentando-se como um elemento integrador e interdisciplinar, que deve efetivar a inserção de alunos e professores na realidade profissional existente. A análise, a reflexão e o retorno das experiências vivenciadas tornam-se elementos indicadores para a pesquisa teórica dos conhecimentos arrolados nos demais Programas de Aprendizagem. A inserção na realidade far-se-á num crescendo que abrangerá desde a observação e análise dos diferentes tipos de atividades profissionais de uma determinada formação, até 0 assumir de projetos específicos, encargos profissionais e outras formas de atuação na empresa/indústria/escola para a qual o al uno está sendo preparado, pois admitamos que o estágio como mundo do trabal ho e como prática social (LDB, 9394/96) leva no seu bojo potencialidades para definir o projeto pedagógico da instituição, integrados nos atributos da mundialização (DELORS, 1996) aceitos e interiorizados no determinante de um projeto consciente, compartilhado e construído entre todos os participantes do projeto de educação e qualificação profissional.

Sal gado propõe que os estágios se constituam em eixo norteador da estruturação curricular: "\{...\} programar o estágio de início ao fim do curso e até mesmo estruturar o currículo através de uma seqüência orgânica de estágios." (SALGAD 0, 1993, p.19).

N este enfoque, o Estágio Supervisionado tem por finalidade propiciar ao al uno uma aproximação da realidade, onde a aprendizagem se efetiva apontando para algumas características tais como responsabilidade, consciência, compromisso, espírito crítico e inovador, além de obter uma visão de totalidade da instituição profissional em que poderá atuar.

0 Estágio Supervisionado é, portanto, um Programa de Aprendizagem integrador, articulando os conhecimentos específicos entre si e, também, os conhecimentos fundamentais do currículo.

Para que se concretize "o estágio como espaço de formação do profissional cidadão é necessário compreendêlo contextualmente, isto é, a partir do currículo no qual está inserido, que por sua vez, deve ser decorrente da política definida pela Instituição para o ensino da graduação. Embora tenha especificidades no que se refere sua operacionalização, a sua discussão, organização, planejamento só poderá se dar no contexto da proposição dos Projetos Pedagógicos dos cursos de graduação." (GISI, SC H U ART Z et al. p. 51)

Pensar sobre a dimensão formadora e social dos estágios pressupõe questionar qual profissional se quer formar para qual sociedade, definindo 0 
perfil e as competências a serem buscadas no processo de formação e, portanto, no estágio curricular supervisionado.

0 papel do docente neste contexto é o de ultrapassar os limites da sala de aula, levando em consideração o contexto sócioeconômico, político e cultural seu - professor - e de seu aluno. D essa forma, o professor supervisor tem o compromisso da reflexão enquanto prática social, para promover a construção de comunidades de aprendizagem em que alunos e professor se apoiem e se estimulem para a reconstrução de saberes e competências.

Pensar reflexivamente leva à indagação, à ação, à pesquisa, à descoberta uma vez que o pensamento reflexivo se faz ativos, prolongado e requerendo cuidadoso exame de toda crença ou hipótese de conhecimento, à luz de argumentos em que se apoia e das conclusões a que chega.

A reflexão é um meio de explicitar uma situação problema e chegar e uma situação satisfatória, pois a real idade concreta é sempre mais complexa e rica que o conhecimento que dela temos, e, portanto, por mais abrangente que seja a nossa compreensão do real, ela não abarca tudo.

\section{3 - A dinâmica da teoria e prática no estágio supervisionado}

Embora diferentes, teoria e prática são por natureza inseparáveis, pois é absurda qualquer tentativa de circunscrevê-las em momentos isolados. A prática que se pretende caracterizar nessas considerações constitui uma mediação entre momentos teóricos que qualitativamente se diferenciam a partir da dinâmica de ação a que dão origem e da qual resultam, fazendo com que cada um deles se configure como uma síntese sempre possível de superação, já que é histórica e relativa.

A teoria e a prática concebidas como dimensão de um mesmo processo unitário se efetivam, segundo Vasquez, por meio de uma dinâmica, em que a teoria orienta a ação, entendida como transformação da realidade e esta, por sua vez, pode reorientar a própria teoria, fazendo-a avançar e progredir. Segundo o mesmo autor, entre ambas existe uma autonomia e dependência mútua relativas, "fazendo parte de um processo histórico-social complexo, no qual algumas vezes, se passa da prática à teoria, e outras desta à prática." (1977)

0 diagrama abaixo elucida mais facilmente a dinamicidade presente no estágio supervisionado, em que teoria e prática se complementam mutuamente: 


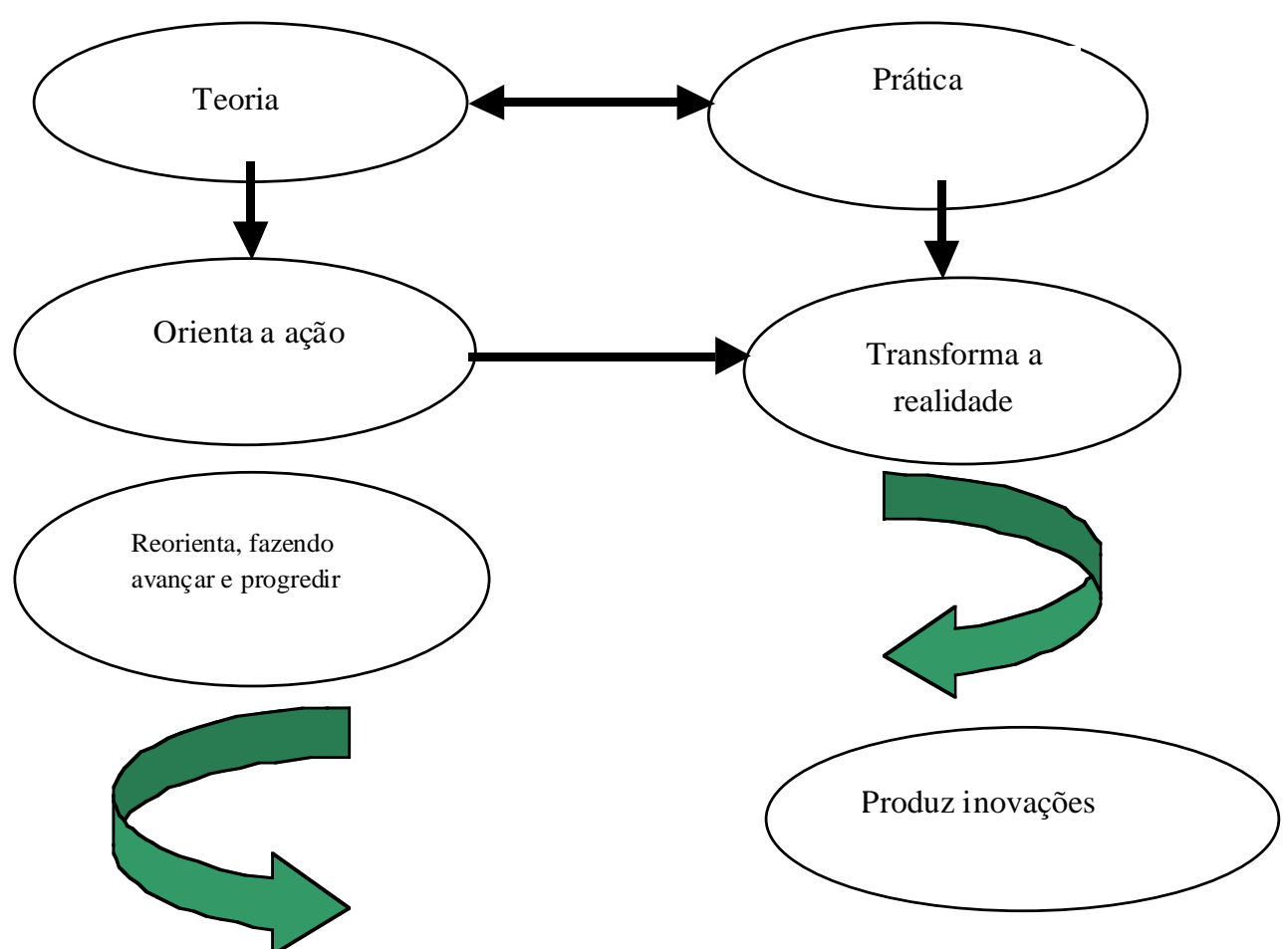

Portanto, essa correlação teoria/prática se converte numa atividade cognoscitiva (conhecer) eteleológica (estabelecer finalidades; antecipar ideal mente uma real idade que ainda não existe e que se quer que exista). Isto requer que se parta do conhecimento (teórico-prático) da realidadequejá existe. Esta realidade é determinada por fatores sociais que a antecedem e por fatores sociais que Ihe são extrínsecos. É desse modo que a atividade teórica possibilita conhecer a realidade (a prática objetiva), tomando-se essa realidade como objeto de conhecimento, como referência, para a seguir, estabelecer-se idealmente a realidade que se quer.

Assim, teoria e prática são indissociáveis, visto que é condição fundamental para preparar-se o futuro profissional para transformar a realidade, pelo seu trabalho, por sua atividade prática, fazen do do seu exercício profissional uma práxis transformadora. (Vasquez)

Q uando se trabal ha integralmente teoria e prática, permitindo que a primeira seja o ponto de reflexão crítica sobre a realidade, a fim de poder compreendêla e transformá-la - o estágio estará sendo um elo de ligação, que certamente culminará numa proposta de inovação criadora, de interferência com vistas à mudança e à busca da qualidade do curso. 


\section{4 - Construindo aptidões e competências}

Portanto, esta concepção de Estágio Supervisionado, a partir das séries iniciais do curso, anula a característica de atividade terminal do curso, constituindo-se num "projeto coletivo", pois segundo o autor citado, em que a prática é uma atividade material, transformadora eajustada a objetivos, cuja finalidadeéa transformação real para determinada necessidade humana - a formação de competências - em que a participação do professor torna-se imprescindível e conduz o futuro profissional a autonomia.

D e acordo com PIM EN TA (1997), cabe ao professor não apenas a tarefa de ensinar desde a organização, análise e decisão dos processos profissionais em aula, na escola, na empresa ou organização profissional como a análise e decisão de políticas da profissão e os conseqüentes resultados destes no processo de humanização.

"N em sempre os estágios contribuem para o desenvolvimento das aptidões e competências desejadas e necessárias devido a dificuldades existentes. Tais dificuldades podem ser atribuídas tanto a organização e planejamento como ao próprio desenvolvimento o que decorre principalmente da falta de aprofundamento das discussões sobre o estágio no contexto do curso no qual se insere." (GISI, SCH UARTZ et al., 2000)

\section{5 - Considerações finais}

Assim, construir/reconstruir aptidões e competências para desenvolver práticas pedagógicas envolve avanços e recuos, pois enfrentamos resistência por parte do ambiente profissional, organizacional, da formação e experiência anteriores muitas vezes condicionadas à racionalidade técnica. É natural que as mudanças sejas lentas, mas um professor deve ter capacidade de refletir sobre as experiências, sair do individual ismo e construir pedagogias mais eficazes.

D esse modo, podemos concluir que o estágio é preparador da práxis transformadora - aí a unidade teoria/prática ser condição fundamental para a operacionalização do curso - que será traduzido em seu projeto pedagógico, pois a prática deve ser entendida numa visão holística de totalidade (holística da realidade). 


\section{Referências bibliográficas}

BRASIL Lei no 9394 de 20 de Dezembro de 1996. Estabelece as Diretrizes e Bases da Educação N acional. Diário oficial da República Federativa do Brasil, Brasil, D F, v. 134, № 248, p. 27, 883-41. 23 dez. 1996, Seção 1

D ELO RS, J. Educação: um tesouro a descobrir. 3. ed., São Paulo: Cortez, 1999.

GISI, M. L. et al.; Revista D iálogo Educacional. Vol. 1, no 2, jul/dez/ 2000. PUCPR.

PIM ENTA, Selma Garrido. 0 estágio na formação de professores. Unidade teoria e prática. 3. ed, São Paulo: Cortez, 1997.

SALGAD O , J. 0 s estágios e o processo de construção da ética e da cidadania. IN AN AIS II Encontro Estadual de estágios de 15 a 17 de setembro de 1993, Curitiba: UFPR/C oordenadoria G eral de Estágios, 1993.

RIBAS, M . H . Construindo as competências. São Paulo: O lho D 'água, 2001. VASQ U EZ, A. S. Filosofia da práxis. 2. ed., Paz eTerra: RJ, 1977.

Recebido em: 06/11/2001 Aprovado em: 19/11/2001 